\title{
Dispersive Solid Phase Extraction Headspace Sampling in Gas Chromatography- Mass Spectrometric Analysis of Volatiles: Application to Separation of Polycyclic Aromatic Hydrocarbons
}

\author{
Zahra Ramezani, ${ }^{\circledR *, a}$ Fatemeh Kardani, ${ }^{a}$ Nadereh Rahbar, ${ }^{a}$ Ahmad Babapoor ${ }^{b}$ and \\ Fariba Bahrami ${ }^{b}$ \\ ${ }^{a}$ Nanotechnology Research Center, Medicinal Chemistry Department, Faculty of Pharmacy, \\ Ahvaz Jundishapur University of Medical Sciences, 234567890 Ahvaz, Iran \\ ${ }^{b}$ Medicinal Chemistry Department, Faculty of Pharmacy, \\ Ahvaz Jundishapur University of Medical Sciences, 6198735533 Ahvaz, Iran
}

\begin{abstract}
For the first time, dispersive solid phase extraction combined with headspace sampling was introduced and applied to separation and pre-concentration of polycyclic aromatic hydrocarbons (PAHs) as representative of volatile and semi-volatile compounds, from aqueous solutions and sediments using multiwall carbon nanotubes (MWCNTs). After adsorption, PAHs were desorbed thermally from the surface of MWCNTs using a gas chromatography mass spectrometry (GC-MS) CombiPAL headspace device or a homemade thermal desorption system. Pre-concentration was maximized through optimization of solution $\mathrm{pH}$, sorbent amount, and extraction time as well as desorption time and temperature of PAHs. The calibration curves were linear in the range 0.005-30 ng mL $\mathrm{mL}^{-1}$ for $13 \mathrm{PAHs}$ at optimum conditions, with the coefficients of determination $\left(\mathrm{R}^{2}\right)$ above 0.992 , and detection limit in the range of 0.0021 to $0.0045 \mathrm{ng} \mathrm{mL}^{-1}$. Reproducibility for all PAHs was between 1.6 and 4.2\%. Method recoveries were in the range of $94.0-102 \%$ for three spiked levels $\left(1,10,20 \mathrm{ng} \mathrm{mL}^{-1}\right)$. The methodology is even better if the selective or specific magnetic sorbent is used.
\end{abstract}

Keywords: dispersive solid phase extraction, headspace sampling, polycyclic aromatic hydrocarbon, gas chromatography mass spectrometry, multiwall carbon nanotubes

\section{Introduction}

Sample preparation is the bottleneck of all instrumental analysis. Depending on the analyte and the instrumental technique, different sample preparation protocols had been introduced and developed. ${ }^{1-9}$ Solid phase extraction (SPE), with advantages of using a lower volume of the sample solution and organic solvents, became a good replacement for tedious classical liquid-liquid extraction (LLE). ${ }^{9} \mathrm{SPE}$ is a multistep sample preparation technique, and the volume of solvents used is still considerable, and a final solvent exchange or volume reduction is required. However, other methods such as dispersive SPE $(\mathrm{dSPE}))^{2,10}$ solid phase micro-extraction (SPME) $)^{6,11-14}$ and its modified forms, ${ }^{10,15}$ stir bar sorptive extraction (SBSE), ${ }^{6}$ liquid phase micro-extraction ${ }^{16-19}$ as well as micro SPE $(\mu \mathrm{SPE})^{11,12,20,21}$ were developed. Although the volume of

*e-mail: zramezani@ajums.ac.ir, zahramezani@gmail.com the organic solvents is reduced extensively in most recent techniques, analysts are still exposed to solvents and may experience health hazards in the longer period of exposure. Headspace solid phase micro-extraction (HS-SPME), ${ }^{22}$ static and dynamic headspace are solvent-free sample preparation techniques that eliminate organic solvents. In HS-SPME, a fiber that is coated with a thin layer of an appropriate sorbent is placed in the headspace above the sample to adsorb volatile or semi-volatile analytes. ${ }^{23,24}$ Finally, the compounds are desorbed thermally in the injection port of a gas chromatograph (GC). The technique is fast and requires no organic solvents. So, application of HS-SPME grows rapidly, and the fibers become commercially available. Drawbacks of commercial HS-SPME fibers are their swelling, the economic cost, and appearance of adhesive compounds in the chromatograms even after prolonged conditioning. When commercial fibers are exposed to the headspace of the samples containing corrosive materials such as the petrochemical 
contaminated water samples, the fiber can be released from the holder. It may be due to the dissolution of the adhesive in volatiles contents of the sample. Also, the adsorption capacity of SPME is limited by the low surface area of the sorbent. SBSE technique was introduced to increase adsorption capacity. In headspace SBSE, the coated stir bar is placed in a container coupled to the injector, and the analytes are thermally desorbed. ${ }^{25,26}$ This technique has some disadvantages such as loss of coating materials due to frictional wear and tear, limited range of the coating commercially available, and additional equipment added to the GC for thermal desorption of the analyte. There was no pre-concentration of analytes in the static headspace. Therefore, the solution volume needs to be increase to compensate for. ${ }^{27}$ Equilibration time also affects the results, and long equilibration is usually required. So, quantitation of a certain analyte by static headspace at trace and ultra-trace levels becomes cumbersome or impossible. Dispersive SPE is one of the most practically feasible and suitable technique, does not require sophisticated equipment and provides high pre-concentration efficiency. ${ }^{12}$ Dispersive solid phase extraction has the advantage of longer contact time, more sorbent solution equilibrium, as well as maximum surface available for analyte adsorption.

The objective of this study is to get use of the advantages of both dispersive solid phase extraction and headspace sampling (dSPE-HS) before gas chromatographic analysis of volatiles or semi-volatiles. This combination makes sample preparation simple, does not require changes in the GC instrument compared to SBSE, and eliminates hazardous organic solvents used in most sample preparation techniques. Polycyclic aromatic hydrocarbons (PAHs) and multiwall carbon nanotubes (MWCNTs) were selected as a model analyte and sorbent, respectively. PAHs are common organic contaminants of water, atmosphere, and sediments samples. ${ }^{18,19,28,29}$ They are harmful to mankind due to their toxicity, mutagenicity, and carcinogenic properties. PAHs residue in water is low due to their low water solubility, and pre-concentration is required for their detection and assay. MWCNTs was previously introduced as effective SPE adsorbent displaying strong adsorption tendency to PAHs. ${ }^{9,30,31}$ So, 13 EPA priority PAHs were pre-concentrated by dispersing MWCNTs in the sample solution at optimized conditions, then adsorbed PAHs were desorbed thermally from the surface of MWCNTs. The present dSPE-HS sampling was coupled to GC-MS to increase the sensitivity. It has been demonstrated that the method was able to determine traces of 13 PAHs in river water and sediment samples.

\section{Experimental}

\section{Chemicals and reagents}

Chrysene, phenanthrene, anthracene, 2-naphtol, 1-naphtol, naphthalene, HPLC-grade acetonitrile, acetone, chloroform, and dichloromethane were supplied from Merck (Darmstadt, Germany). A $1 \mathrm{~mL}$ vial containing 13 PAHs (500 $\left.\mu \mathrm{g} \mathrm{mL}^{-1}\right)$ in hexane was purchased from Supelco (Bellefonte, Pennsylvania, USA). MWCNTs with diameters in the range $20-40 \mathrm{~nm}$, length of 5-15 $\mu \mathrm{m}$, and purity $95 \%$ were purchased from the Chengdu Organic Chemicals, Chinese Academy of Science (Chengdu, China). Individual stock standard solutions for 6 out of 13 PAHs were prepared in GC grade methanol at a concentration of $1000 \mu \mathrm{g} \mathrm{L}^{-1}$ and stored at $4{ }^{\circ} \mathrm{C}$ before use. A working standard solution containing target compounds at a concentration of $100 \mu \mathrm{g} \mathrm{L}^{-1}$ was prepared from the stock standards by appropriate dilution. Ultrapure water (TKA, Niederelbert, Germany) was used whenever required.

\section{Gas chromatographic analysis}

A 7890A Agilent gas chromatograph (Agilent, Little Falls, DE, USA) equipped with an MSD-5975C mass selective detector and a CTC CombiPal auto-sampler (Zwingen, Switzerland) was used for GC-MS analysis. Instrument control and data collection were provided by ChemStation software, version 5.51. Wiley 7.1 and NIST mass spectral libraries were used to identify the compounds in scan mode. Ten-milliliter headspace vials with polytetrafluoroethylene (PFTE) coated silicone septa and magnetic cap (Microliter Analytical Supplies, Suwanee, GA, USA) were used in the desorption steps. Separation was performed on a DB-5MS fused silica capillary column $(30 \mathrm{~m} \times 0.25 \mathrm{~mm}$ i.d., $0.25 \mu \mathrm{m}$ film thickness) purchased from J\&W Scientific (Folsom, CA, USA). Helium with the purity of $99.9999 \%$ was used as carrier gas, with a flow rate of $1 \mathrm{~mL} \mathrm{~min}{ }^{-1}$. The oven temperature was initiated at $40{ }^{\circ} \mathrm{C}$ and kept at this temperature for $2 \mathrm{~min}$, then raised to $170{ }^{\circ} \mathrm{C}$ with $20{ }^{\circ} \mathrm{C} \mathrm{min}{ }^{-1}$ stay for $0.5 \mathrm{~min}$ then increased to $280{ }^{\circ} \mathrm{C}$ with the rate of $10^{\circ} \mathrm{C} \mathrm{min}^{-1}$. Total run time was $20 \mathrm{~min}$. The injection was performed at $280^{\circ} \mathrm{C}$ in the split mode (ratio 20:1). The transfer line and ion source were set at 250 and $200{ }^{\circ} \mathrm{C}$, respectively. The electron impact energy was set at $70 \mathrm{eV}$, and the mass range was from $\mathrm{m} / \mathrm{z} 50$ to 600. Analyses were performed using quantitative secondary ion monitoring (SIM) with ion qualifiers that are identified in Table 1. 
Table 1. Retention time, ion qualifier and validation parameters for 13 PAHs analyzed by selected ion monitoring (SIM) GC-MS after pre-concentration by the present methodology

\begin{tabular}{|c|c|c|c|c|c|c|}
\hline $\mathrm{PAH}$ & $t_{R} / \min$ & $\begin{array}{l}\text { Qualifier } \\
\text { ion }(m / z)\end{array}$ & $\begin{array}{l}\text { Linear range / } \\
\quad\left(\mu \mathrm{g} \mathrm{L}^{-1}\right)\end{array}$ & $\begin{array}{l}\mathrm{LOD} / \\
\left(\mu \mathrm{g} \mathrm{L}^{-1}\right)\end{array}$ & Calibration line equation & $\mathrm{R}^{2}$ \\
\hline Naphthalene & 5.73 & 128 & $30-0.01$ & 0.0041 & $y=(19075 \pm 98) x+(18168 \pm 135)$ & 0.996 \\
\hline Acenaphthylene & 9.82 & 152 & $30-0.01$ & 0.0038 & $y=(12073 \pm 54) x+(10714209 \pm 152)$ & 0.992 \\
\hline Acenaphthene & 10.88 & 153 & $30-0.01$ & 0.0045 & $y=(61929 \pm 87) x+(1867329 \pm 167)$ & 0.993 \\
\hline Fluorene & 11.96 & 166 & $30-0.005$ & 0.0021 & $y=(19768 \pm 65) x+(38563221 \pm 178)$ & 0.997 \\
\hline Phenanthrene & 12.78 & 178 & $30-0.005$ & 0.003 & $y=(99321 \pm 120) x+(2021484 \pm 213)$ & 0.997 \\
\hline Anthracene & 13.36 & 178 & $30-0.01$ & 0.0028 & $y=(20521 \pm 76) x+(23464 \pm 89)$ & 0.995 \\
\hline Fluoranthene & 13.60 & 202 & $30-0.01$ & 0.0036 & $y=(15925 \pm 34) x+(3178421 \pm 245)$ & 0.997 \\
\hline Pyrene & 14.57 & 202 & $30-0.01$ & 0.0034 & $y=(14083 \pm 27) x+(5121219 \pm 154)$ & 0.992 \\
\hline Chrysene & 15.79 & 228 & $30-0.01$ & 0.0042 & $y=(12136 \pm 28) x+(1152671 \pm 102)$ & 0.995 \\
\hline Benzo $[a]$ anthracene & 17.38 & 228 & $30-0.01$ & 0.0038 & $y=(15177 \pm 65) x+(1124791 \pm 112)$ & 0.993 \\
\hline Benzo $[b]$ fluoranthene & 19.51 & 253 & $30-0.01$ & 0.0032 & $y=(81165 \pm 63) x+(1299114 \pm 82)$ & 0.992 \\
\hline Benzo $[k]$ fluoranthene & 22.46 & 253 & $30-0.01$ & 0.0029 & $y=(19262 \pm 35) x+(25422 \pm 78)$ & 0.993 \\
\hline Benzo $[a]$ pyrene & 26.39 & 253 & $30-0.01$ & 0.0044 & $y=(1644 \pm 17) x+(27427 \pm 58)$ & 0.994 \\
\hline
\end{tabular}

PAH: polycyclic aromatic hydrocarbon; $t_{\mathbb{R}}$ : retention time; LOD: limit of detection; $\mathrm{R}^{2}$ : determination coefficient.

\section{General procedure}

Ten milligrams of MWCNTs and $5 \mathrm{~mL}$ of PAHs standard with appropriate concentrations or sample solutions were added to a $10 \mathrm{~mL}$ beaker and stirred for $30 \mathrm{~min}$. Then, the resulting mixture was centrifuged for 5 min at 10,000 rpm. The supernatant was separated, and MWCNTs was dried under a gentle nitrogen atmosphere. The MWCNTs was transferred into a $10 \mathrm{~mL}$ headspace vial and placed on the sample trays of CTC CombiPal auto-sampler. The vial was shaken for $5 \mathrm{~min}$ at $220^{\circ} \mathrm{C}$ in CombiPal heater compartment, then after $5 \mathrm{~s}, 1 \mathrm{~mL}$ of the headspace was injected to GC-MS. In case of manual injection, the vial containing MWCNTs was placed on the heater in an oil bath, heated to $220^{\circ} \mathrm{C}$ for $5 \mathrm{~min}$. Finally, $1 \mathrm{~mL}$ of headspace was injected into GC using a Hamilton gas-tight syringe. The whole process is schematically shown in Figure 1.

\section{Real sample preparation}

Water samples were collected from Karoon River located in Khuzestan Province (Khuzestan, Iran) and

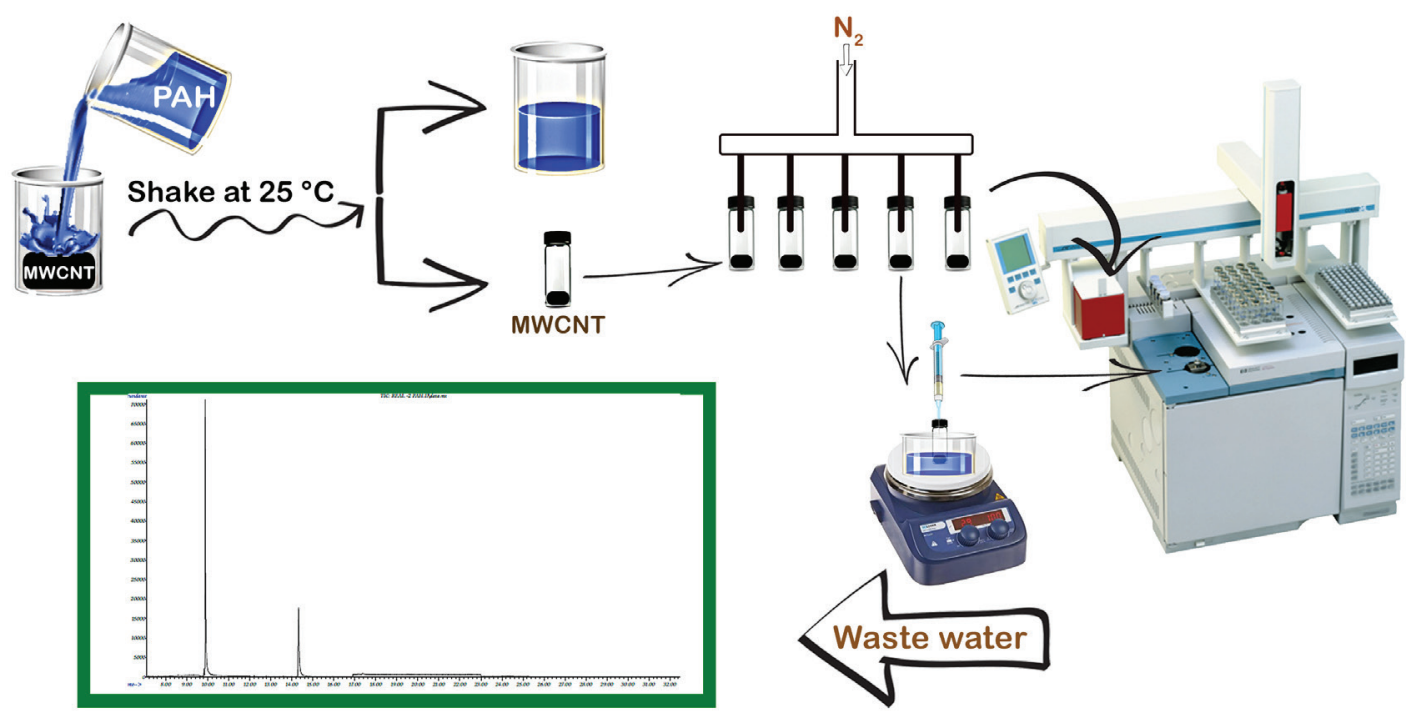

Figure 1. Schematic representation of the whole dSPE-HS procedure in PAHs analysis. 
transferred to the laboratory in dark glass bottles on ice. The river water samples were filtered through Whatman No. 42 filter paper before analysis and stored in the refrigerator, kept away from light. The $\mathrm{pH}$ of samples was adjusted to 3 by $20 \mathrm{mM}$ phosphate buffer. The separation procedure was applied based on the above-mentioned method ("General procedure" sub-section).

PAH were extracted from sediment samples according to the standard procedure. ${ }^{32}$ To briefly describe, a $3.0 \mathrm{~g}$ soil sample was mixed with $10 \mathrm{~mL} n$-hexane and dichloromethane (1:1). The resulting mixture was sonicated for $30 \mathrm{~min}$. Then, the sediments were separated from the solution after centrifuging the mixture at $4000 \mathrm{rpm}$ for $10 \mathrm{~min}$. The solution was passed through the filter paper to remove any solid residue. The clear solution was stored in a dark clean container. The extraction was repeated three times on each sediment and the resulting supernatant was added to the first extract. The solvent volume of the extract was reduced by passing nitrogen gas through the solution for about $20 \mathrm{~min}$ (final volume of $2 \mathrm{~mL}$ ). Finally, $100 \mu \mathrm{L}$ of the concentrated extract was added to $5 \mathrm{~mL}$ distilled water and the present pre-concentration protocol was applied ("General procedure" sub-section).

\section{Results and Discussion}

\section{Optimization of extraction conditions}

In common sense, recovery of the present extraction techniques could be influenced by several experimental and instrumental conditions such as amount of extractor (here MWCNTs), extraction time, shaking time, desorption temperature as well as solution $\mathrm{pH}$. All these parameters were optimized and explained separately.

\section{Amount of MWCNTs}

The sorbents capacity towards an analyte is limited and determines the amount of sorbents used in each separation and pre-concentration procedure. It was previously reported ${ }^{9}$ that MWCNT is an excellent sorbent for PAHs. So, the effect of the low amount of MWCNTs, 3 to $15 \mathrm{mg}$, on the PAHs recoveries was studied. The results in Figure 2a indicate direct relation between the recoveries and the amount of MWCNTs up to $10 \mathrm{mg}$ (high available adsorption site for the PAHs). It means that MWCNTs approximately reached the highest capacity toward a tested amount of PAHs at this point. Therefore, PAHs $\left(1 \mu \mathrm{g} \mathrm{L}^{-1}\right)$ were efficiently adsorbed on MWCNTs when $10 \mathrm{mg}$ of MWCNTs was used. Further increase in the amount of MWCNTs has a slight effect on the recoveries of PAHs. Insufficient adsorption was observed for PAHs at
MWCNTs amounts smaller than $5 \mathrm{mg}$, which may be is due to adsorbents losses during centrifugation and separation.
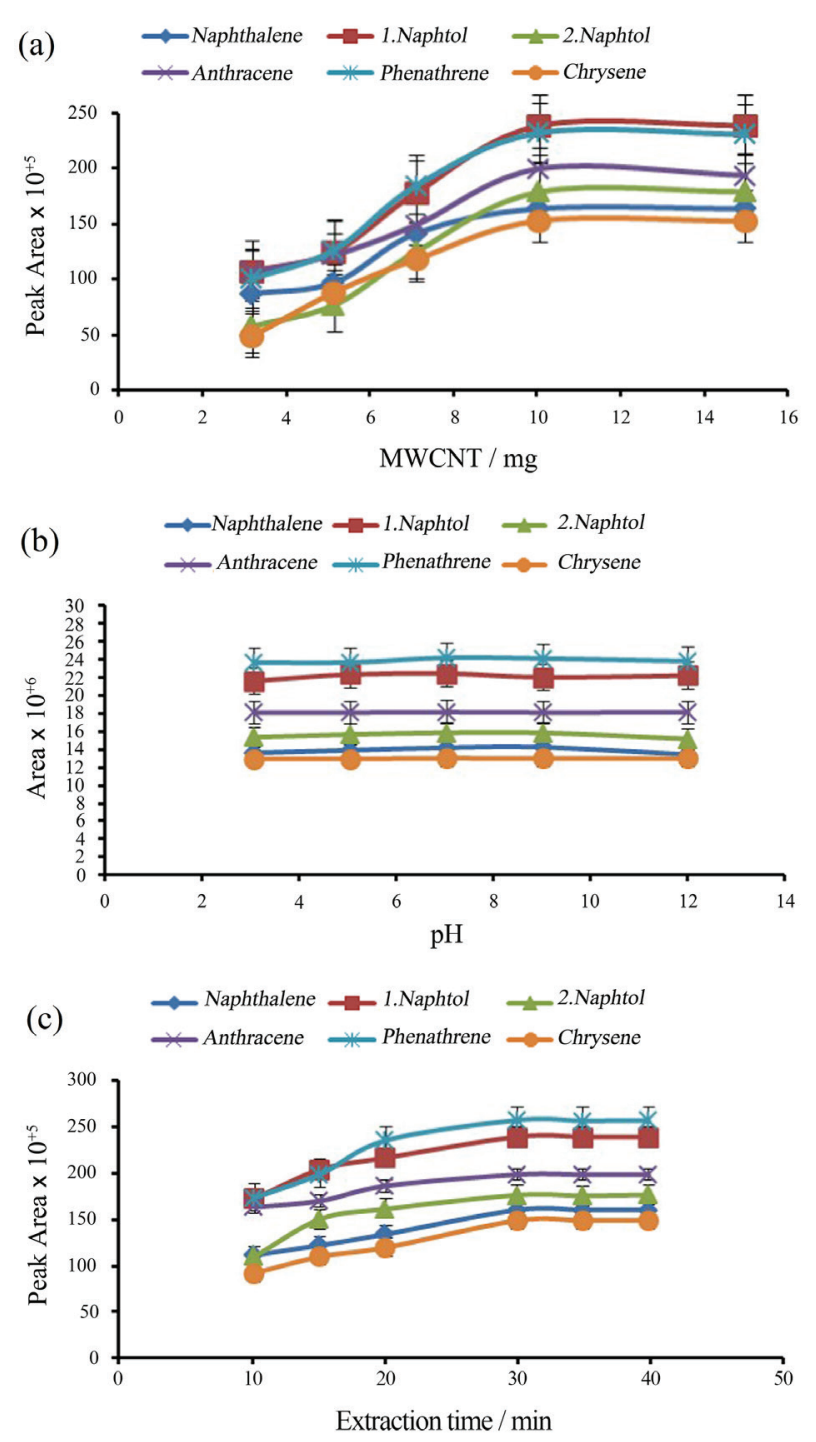

Figure 2. The effect of (a) MWCNTs amounts, conditions: $\mathrm{pH}=5$; extraction time $=30 \mathrm{~min}$; (b) $\mathrm{pH}$, conditions: $\mathrm{MWCNTs}=10 \mathrm{mg}$; extraction time $=30 \mathrm{~min}$ and $(\mathrm{c})$ extraction time, conditions: $\mathrm{pH}=7$; MWCNTs $=10 \mathrm{mg}$, on the adsorption of $1 \mu \mathrm{g} \mathrm{L}-1$ of 6 PAHs. GC conditions are described in the "Gas chromatographic analysis" sub-section.

\section{Effect of solution $\mathrm{pH}$}

Figure $2 \mathrm{~b}$ demonstrates the effect of solution $\mathrm{pH}$ on the PAHs extraction in a $\mathrm{pH}$ range of 3 to 9 . The charges on the surface of MWCNTs vary with solution $\mathrm{pH}$, thereby changing the stability of MWCNTs formed via static electric interaction, and in turn the dSPE-HS of PAHs. Figure $2 \mathrm{~b}$ shows no significant influence of solution $\mathrm{pH}$ on the extraction of PAHs in the studied range. Therefore, $\mathrm{pH}$ adjustment is not necessary. PAHs are adsorbed on the surface of MWCNTs by $\pi-\pi$ interaction and it is not influenced by $\mathrm{pH}$ changes. 


\section{Effect of extraction time}

Extraction time of the analytes onto a specific sorbent determines the kinetic of adsorption. For the tested PAHs in the present separation and pre-concentration method, the effect of extraction time from 10 to 40 min was examined. The results in Figure 2c show that the recoveries improve with the increase in extraction time from 10 to $30 \mathrm{~min}$ and then reach a plateau. The increase in the extraction time is beneficial to the adsorption of analytes until adsorption equilibrium establishes. The recoveries reach the plateau at equilibrium. Therefore, $30 \mathrm{~min}$ was chosen as the extraction time.

\section{Effect of shaking time and desorption temperature}

The migration of PAHs into the headspace phase depends not only on their volatility, but also on their affinity for solid phase (MWCNTs). Furthermore, if MWCNTs inside the sample vial are left for a while, the relative concentrations of a compound between solid and gas phase will reach equilibrium. There is a thermodynamic energy associated with the presence of each PAH in the headspace phase and the solid phase. These thermodynamic properties indicate the distribution of PAHs between the two phases. This distribution is represented by the distribution ratio. Distribution ratio will be strongly affected by temperature and to some extent by shaking the media. Therefore, equilibrium temperature and shaking time were optimized to increase pre-concentration and reproducibility of the results. In this work an automatic headspace procedure was applied to desorb PAHs from MWCNTs surface thermally. A CTC CombiPal auto-sampler, which was programmed using Cycle Composer software version 1.4.0 or a homemade desorption system, was used for automation of the procedure. In CombiPal auto-sampler, a temperature controlled agitator tray was programmed to apply temperature in the range of 120 to $220{ }^{\circ} \mathrm{C}$ for PAHs desorption from MWCNTs surface. Agitator shaking time (Figure 3a) was optimized in the range of 5 to 20 s. Shaking time did not show any considerable effect on the release of PAHs from MWCNTs. The effect of temperature on PAHs release is shown in Figure $3 \mathrm{~b}$. The experiment results revealed that the released amount of analytes (corresponding to the peak areas) increased as the extraction temperature raised. Temperature higher than $220{ }^{\circ} \mathrm{C}$ was not investigated because of the temperature limitation of the CombiPal heater headspace compartment. At $220^{\circ} \mathrm{C}$, desorption of PAHs from the sorbent surfaces is high. Therefore, desorbed PAHs at $220^{\circ} \mathrm{C}$ were injected to GC-MS. To show possible routine use of the present protocol in volatiles and semi-volatiles separation and preconcentration, a home-made desorption system was also designed. In this regard, MWCNTs in $10 \mathrm{~mL}$ GC vials were heated in oil bath at $200{ }^{\circ} \mathrm{C}$ for $2 \mathrm{~min}$. The results were exactly the same as with automatic system.
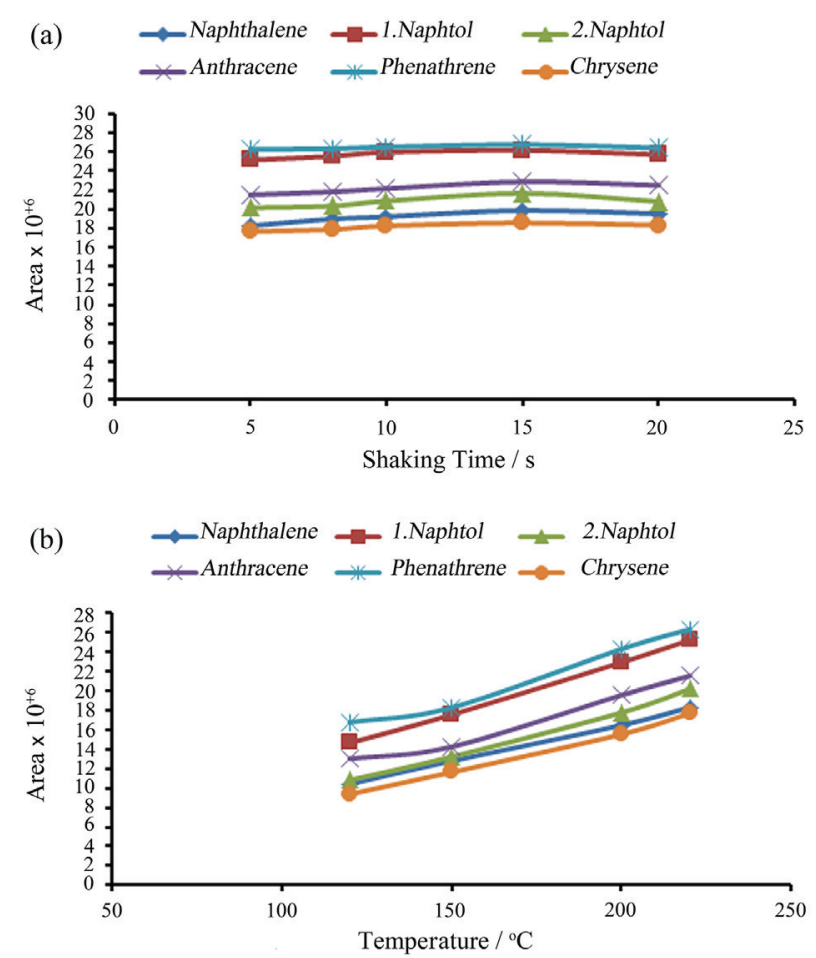

Figure 3. Effect of (a) shaking time and (b) temperature on PAHs desorption from MWCNTs surface.

Method validation

Under the optimized conditions, linearity, detection (LOD) and quantification limits, and interand intradays precision were determined to evaluate the applicability of dSPE-HS in PAHs assay. The results are listed in Table 1. The limits of detections and quantifications were calculated as 3 and 10 times standard deviations (SD) each divided by the slope of the calibration curve (m), respectively. SD is the standard deviation of 10 replicates at the lower concentration of calibration curves $\left(0.005 \mu \mathrm{g} \mathrm{L}^{-1}\right.$ for fluorene and phenanthrene, and $0.01 \mu \mathrm{g} \mathrm{\textrm {L } ^ { - 1 }}$ for the rest). Relative standard deviations (RSD) in a day and three consecutive days were obtained at concentrations of $5 \mu \mathrm{g} \mathrm{L}{ }^{-1}$ for 13 PAHs (3 replicates). All coefficients of variation $(\mathrm{CV})$ were lower than $4.2 \%$. MWCNTs were recycled five times after washing with $\mathrm{MeOH}$.

\section{Real sample analysis}

In every new analytical procedure, the ability of the method in evaluation and measurements of the analyte in real samples with high accuracy and precision is 
required. Therefore, to evaluate the reliability of the present pre-concentration and separation technique, two environmental samples, river water and sediments, were selected. River water was used without any pretreatment, but PAHs contents of sediments were originally extracted by ultrasonic. Relative extraction recovery ( $R R$, in percentage) was determined by spiking three different concentrations of standards in the sample matrix. As can be seen in Table 2, the RSDs are less than $4.5 \%$, and the recoveries are more than $92.0 \%$. Representative chromatograms of standards and a river water sample are shown in Figure 4. As it is illustrated in Figure 4b, SIM chromatogram of river water sample is crowded, and the matrix may affect the results. Therefore, matrix effect (ME, in percentage) was determined for the detected PAHs in river water by determining the peak area for $10 \mu \mathrm{g} \mathrm{mL} \mathrm{m}^{-1}$ standard added in the solvent, and the river water (in the matrix) using equation 1.

$\operatorname{ME}(\%)=\frac{\text { Standard peak area in matrix }}{\text { Standard peak area in solvent }} \times 100$
$\operatorname{ME}(\%)$ was 102.0 and $94.0 \%$ for phenanthrene and anthracene, respectively. The peaks that appeared in the chromatograms are due to the adsorption ability of MWCNTs towards a vast variety of compounds. But $\operatorname{ME}(\%)$ showed that they do not have any considerable effect on the target analyte. Process efficiency (PE) for the two mentioned PAHs, calculated by equation 2, are 95.88 and 92.31 , consequently.

$\mathrm{PE}=\frac{\mathrm{ME}(\%) \times \mathrm{RR}(\%)}{100}$

\section{Comparison of the present method with previously reported ones}

Different pre-concentration techniques used for PAHs were compared with the present procedure regarding LODs, number of PAHs tested, sample preparation procedures, and instrumental method. Table 3 demonstrates that the present pre-concentration method performs as well as or better than other previously reported techniques. Organic solvents were used in most of the

Table 2. Analysis of river water and sediment for PAHs by the present pre-concentration method coupled to GC-MS

\begin{tabular}{|c|c|c|c|c|c|}
\hline \multirow{2}{*}{ Sample } & \multirow{2}{*}{ Analyte } & \multirow{2}{*}{$\begin{array}{c}\text { Blank sample / } \\
\left(\mu \mathrm{g} \mathrm{L}^{-1}\right)\end{array}$} & \multicolumn{3}{|c|}{ Spiked real samples recovery (RSD / \%) / \% } \\
\hline & & & $1 \mu \mathrm{g} \mathrm{L}^{-1}$ & $10 \mu \mathrm{g} \mathrm{L}^{-1}$ & $20 \mu \mathrm{g} \mathrm{L}^{-1}$ \\
\hline \multirow{13}{*}{ River water } & naphthalene & n.d & $96.0(2.5)$ & $94.0(2.7)$ & $101.0(2.3)$ \\
\hline & acenaphthylene & n.d & $98.0(3.3)$ & $96.0(2.1)$ & $96.0(3.7)$ \\
\hline & acenaphthene & n.d & $96.0(3.2)$ & $99.0(3.7)$ & $102.0(2.5)$ \\
\hline & fluorene & n.d & $96.0(3.8)$ & $94.0(3.1)$ & $94.0(2.8)$ \\
\hline & phenanthrene & 5.4 & $94.0(4.2)$ & $101.0(2.7)$ & $98.0(3.7)$ \\
\hline & anthracene & 3.1 & $100.3(3.3)$ & $98.2(1.6)$ & $99.4(2.9)$ \\
\hline & fluoranthene & n.d & $99.0(3.8)$ & $95.2(3.6)$ & $98.2(3.8)$ \\
\hline & pyrene & n.d & $95.2(3.2)$ & $98.5(3.7)$ & $99.5(3.2)$ \\
\hline & chrysene & n.d & $100.3(3.7)$ & $101.5(3.9)$ & $101.0(3.8)$ \\
\hline & benzo $[a]$ anthracene & n.d & $98.0(4.0)$ & $101.5(3.9)$ & $99.1(3.5)$ \\
\hline & benzo $[b]$ fluoranthene & n.d & $98.2(3.8)$ & $96.0(2.7)$ & $100.5(3.2)$ \\
\hline & benzo $[k]$ fluoranthene & n.d & $95.0(3.2)$ & $98.0(4.1)$ & $99.1(4.2)$ \\
\hline & benzo[a]pyrene & n.d & $97.2(3.1)$ & $96.7(3.2)$ & $98.6(4.2)$ \\
\hline \multirow{13}{*}{ Sediment } & naphthalene & n.d & $95.5(2.8)$ & $96.8(2.4)$ & $93.9(2.4)$ \\
\hline & acenaphthylene & n.d & $94.0(2.8)$ & $102.0(4.2)$ & $102.0(2.5)$ \\
\hline & acenaphthene & n.d & $98.0(4.1)$ & $94.0(3.1)$ & $94.0(2.8)$ \\
\hline & fluorene & n.d & $94.0(4.2)$ & $101.0(2.7)$ & $98.0(3.7)$ \\
\hline & phenanthrene & 2.1 & $100.3(3.3)$ & $98.4(2.3)$ & $99.4(2.9)$ \\
\hline & anthracene & 0.8 & $99.0(3.8)$ & $98.6(3.2)$ & $98.2(3.8)$ \\
\hline & fluoranthene & n.d & $95.2(3.2)$ & $96.8(4.1)$ & $99.5(3.2)$ \\
\hline & pyrene & n.d & $100.3(3.7)$ & $98.5(3.9)$ & $95.7(2.4)$ \\
\hline & chrysene & n.d & $98.0(4.0)$ & $102.5(2.3)$ & $99.1(3.5)$ \\
\hline & benzo $[a]$ anthracene & n.d & $95.5(3.8)$ & $97.0(3.3)$ & $100.5(3.2)$ \\
\hline & benzo $[b]$ fluoranthene & n.d & $96.8(3.2)$ & $98.5(3.7)$ & $96.8(4.2)$ \\
\hline & benzo $[k]$ fluoranthene & n.d & $98.4(2.5)$ & $98.3(3.3)$ & $98.2(2.3)$ \\
\hline & benzo $[a]$ pyrene & n.d & $96.5(3.3)$ & $95.8(3.6)$ & $97.4(3.7)$ \\
\hline
\end{tabular}

RSD: relative standard deviation; n.d: not detected. 
(a)

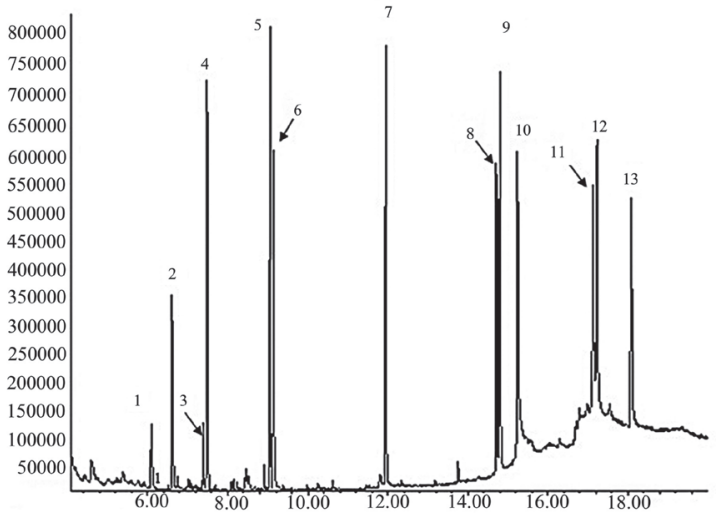

(b)

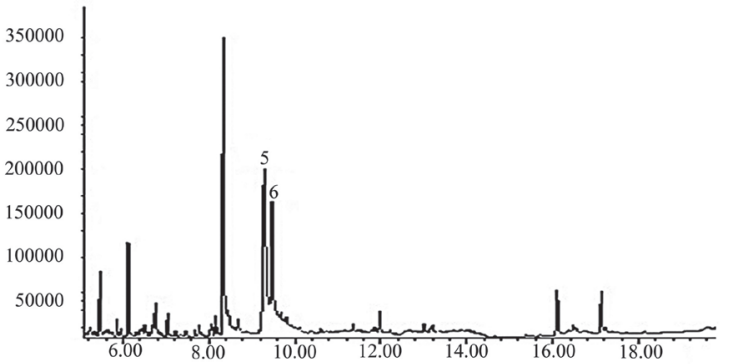

Figure 4. Total ion chromatogram for (a) standard aqueous mixture of 13 PAHs (10 $\mathrm{ng} \mathrm{mL}^{-1}$ ) and (b) PAHs detected in river water sample by SIM-GC-MS after separation and pre-concentration by the proposed procedure (1: naphthalene; 2 : acenaphthylene; 3 : acenaphthene; 4: fluorene; 5: phenanthrene; 6: anthracene; 7: fluoranthene; 8: pyrene; 9: chrysene; 10: benzo $[a]$ anthracene; 11 : benzo $[b]$ fluoranthene; 12 : benzo $[k]$ fluoranthene; 13: benzo $[a]$ pyrene). listed researches. The amount of MWCNTs in this method is $10 \mathrm{mg}$ and is lower than that of Ma et al. ${ }^{9}(150 \mathrm{mg})$. In a recently published work of our research groups, a synthesized amphoteric magnetic sorbent was checked for its ability in adsorption of volatile in edible oils by the present method. ${ }^{27}$

\section{Conclusions}

To the best of our knowledge, it is the first time that dispersive solid phase extraction is followed by headspace sampling for extraction, pre-concentration, and analysis of the volatiles and semi-volatiles with no organic solvents. The present technique separates and pre-concentrates PAHs from the solution without the need of any hazardous organic solvents. This methodology reduces the number of steps in separation, and can be considered as a fast and green pre-concentration procedure. With the magnetic sorbent, this technique becomes more user-friendly and its routine use becomes possible. Therefore, this protocol can be extended to any other volatiles compounds using different sorbents, especially magnetic based materials. It is also a simple and fast technique for determination of volatiles and semi-volatiles in the atmosphere after adsorption on the suitable sorbents, with no need for dSPE.

Table 3. Comparison of the present sample preparation method with those reported in the literature using carbon-based sorbents for PAHs

\begin{tabular}{|c|c|c|c|c|c|}
\hline Sorbent type & Analytical technique & Analyte & $\begin{array}{l}\text { Sample preparation } \\
\text { method }\end{array}$ & $\mathrm{LOD} /\left(\mathrm{ng} \mathrm{mL} \mathrm{mL}^{-1}\right)$ & Reference \\
\hline MWCNT & GC-MS & $16 \mathrm{PAHs}$ & SPE & $0.002-0.0085$ & 9 \\
\hline MWCNT & GC-MS & 16 PAHs & $\mu \mathrm{SPE}$ & $0.0042-0.0465$ & 30 \\
\hline MWCNT & GC-MS & 16 PAHs & $\mu$ column SPE & $0.001-0.15$ & 31 \\
\hline PEG grafted MWCNT & GC-FID & 4 PAHs & SPME & $0.001-0.05$ & 33 \\
\hline G-sulfonated & GC-MS & 7 PAHs & $\mu \mathrm{SPE}$ & $0.0008-0.0039$ & 34 \\
\hline G & GC-MS & 16 PAHs & SBSE & $0.005-0.429$ & 35 \\
\hline Nanohorn & GC-MS/MS & PAHs & $\mathrm{d} \mu \mathrm{SPE}$ & $0.03-0.06$ & 36 \\
\hline- & HPLC & PAHs & DLLME & $0.04-0.6$ & 19 \\
\hline MCFG & GC-MS & 7 PAHs & $\mu \mathrm{SPE}$ & $0.0002-0.0018$ & 11 \\
\hline $\mathrm{G}-\mathrm{Fe}_{3} \mathrm{O}_{4}$ & GC-MS & 16 PAHs & dSPE & $0.009-0.018$ & 37 \\
\hline MWCNTs & GC-MS & 13 PAHs & dSPE-HS & $0.0021-0.0045$ & this work \\
\hline
\end{tabular}

LOD: limit of detection; MWCNT: multiwall carbon nanotubes; PEG: polyethelyen glycole; G: graphene; MCFG: magnetic chitosan functionalized graphene oxide; $\mathrm{G}_{-} \mathrm{Fe}_{3} \mathrm{O}_{4}: \mathrm{Fe}_{3} \mathrm{O}_{4}$ magnetic nanoparticle graphene; GC-MS: gas chromatography mass spectrometry; GC-FID: gas chromatography-flame ionization detector; HPLC: high-performance liquid chromatography; PAH: polycyclic aromatic hydrocarbon; SPE: solid phase extraction; $\mu$ SPE: micro solid phase extraction; SPME: solid phase micro-extraction; SBSE: stir bar sorptive extraction; DLLME: dispersive liquid-liquid extraction; dSPE: dispersive solid phase extraction; dSPE-HS: headspace dispersive solid phase extraction. 


\section{Acknowledgments}

The authors' thanks go to Ahvaz Jundishapur University of Medical Sciences, research deputy who support this work under grant No. N29.

\section{References}

1. Vyviurska, O.; Spanik, I.; Acta Chim. Slov. 2014, 7, 77.

2. Safdarian, M.; Ramezani, Z.; Ghadiri, A. A.; J. Chromatogr. A 2016, 1455, 28.

3. Regnery, J.; Coday, B. D.; Riley, S. M.; Cath, T. Y.; Anal. Methods 2016, 8, 2058.

4. Wen, Y.; Chen, L.; Li, J.; Liu, D.; Chen, L.; TrAC, Trends Anal. Chem. 2014, 59, 26.

5. Huang, K.-J.; Liu, Y.-J.; Li, J.; Gan, T.; Liu, Y.-M.; Anal. Methods 2014, 6, 194.

6. Farajzadeh, M. A.; Khoshmaram, L.; Sheykhizadeh, S.; Anal. Bioanal. Chem. Res. 2014, $1,1$.

7. Ruan, X.; Yang, Z.; Xie, H.; Xiong, W.; Pan, Z.; Chen, L.; Anal. Methods 2013, 5, 1205.

8. Ou-Yang, C.-F.; Liu, J.-Y.; Kao, H.-M.; Wang, J.-H.; Liu, S.-P.; Wang, J.-L.; Anal. Methods 2013, 5, 6874.

9. Ma, J.; Xiao, R.; Li, J.; Yu, J.; Zhang, Y.; Chen, L.; J. Chromatogr. A 2010, 1217, 5462.

10. Bunkoed, O.; Kanatharana, P.; Microchim. Acta 2015, 182, 1519.

11. Naing, N. N.; Yau Li, S. F.; Lee, H. K.; J. Chromatogr. A 2016 , 1440, 23.

12. Naing, N. N.; Li, S. F.; Lee, H. K.; J. Chromatogr. A 2016, 1458 , 25 .

13. Jelen, H. H.; Gracka, A.; J. Chromatogr. A 2015, 1418, 200.

14. Arthur, C. L.; Pawliszyn, J.; Anal. Chem. 1990, 62, 2145.

15. Loh, S. H.; Sanagi, M. M.; Wan Ibrahim, W. A.; Hasan, M. N.; Talanta 2013, 106, 200.

16. Rezaee, M.; Assadi, Y.; Hosseini, M. R. M.; Aghaee, E.; Ahmadi, F.; Berijani, S.; J. Chromatogr. A 2006, 1116, 1.

17. Tobiszewski, M.; Bigus, P.; Namiesnik, J.; Anal. Methods 2014, 6,6678 .
18. Zhu, J.; Wang, Q.; Li, M.; Ren, L.; Zheng, B.; Zou, X.; Anal. Methods 2017, 9, 1855.

19. Arghavani-Beydokhti, S.; Rajabi, M.; Bazregar, M.; Asghari, A.; Anal. Methods 2017, 9, 1732.

20. Naing, N. N.; Li, S. F. Y.; Lee, H. K.; J. Chromatogr. A 2016 , 1458, 25.

21. Zainal Abidin, N. N.; Sanagi, M. M.; Wan Ibrahim, W. A.; Endud, S.; Md Shukri, D. S.; Anal. Methods 2014, 6, 5512.

22. Zhang, Z.; Pawliszyn, J.; Anal. Chem. 1993, 65, 1843.

23. Saeedi, I.; Hashemi, P.; Ramezani, Z.; Badiei, A.; Anal. Methods 2015, 7, 10185.

24. Ramezani, Z.; Saeedi, I.; Hashemi, P.; Anal. Methods 2018, 10, 1379.

25. Wen, Y.; Ontañon, I.; Ferreira, V.; Lopez, R.; Food Chem. 2018, 255,235 .

26. Tölgyessy, P.; Nagyová, S.; Sládkovičová, M.; J. Chromatogr. A 2017, 1494, 77.

27. Safdarian, M.; Ramezani, Z.; Colloids Surf., A 2018, 541, 97.

28. Sulej-Suchomska, A. M.; Polkowska, Z.; Chmiel, T.; Dymerski, T. M.; Kokot, Z. J.; Namiesnik, J.; Anal. Methods 2016, 8, 4509.

29. Ruan, X.; Lu, Q.; Yang, Z.; Anal. Methods 2016, 8, 1690.

30. Guo, L.; Lee, H. K.; J. Chromatogr. A 2011, 1218, 9321.

31. Wu, H.; Wang, X.; Liu, B.; Lu, J.; Du, B.; Zhang, L.; Ji, J.; Yue, Q.; Han, B.; J. Chromatogr. A 2010, 1217, 2911.

32. Santos, M. D. R.; Cerqueira, M. R. F.; de Oliveira, M. A. L.; Matos, R. C.; Matos, M. A. C.; Anal. Methods 2014, 6, 1650.

33. Sarafraz-Yazdi, A.; Ghaemi, F.; Amiri, A.; Microchim. Acta 2012, 176, 317.

34. Zhang, H.; Low, W. P.; Lee, H. K.; J. Chromatogr. A 2012, 1233 , 16.

35. Luo, Y.-B.; Cheng, J.-S.; Ma, Q.; Feng, Y.-Q.; Li, J.-H.; Anal. Methods 2011, 3, 92.

36. Jiménez-Soto, J. M.; Cárdenas, S.; Valcárcel, M.; Anal. Chim. Acta 2012, 714, 76.

37. Zhang, S.; Wu, W.; Zheng, Q.; Anal. Methods 2015, 7, 9587.

Submitted: August 21, 2018 Published online: October 8, 2018 